\title{
Air Pollution and Health: Ever Widening Spectrum
}

\author{
Arun Kumar Sharma \\ Department of Community Medicine \\ University College of Medical Sciences and Guru Teg Bahadur Hospital, Delhi, India. \\ arsharma62@gmail.com
}

$\mathrm{T}$ obacco smoke and air pollution were ranked 3rd and 5th respectively among the risk factors for mortality among citizens of all ages and sexes in 2017 [1]. More than $90 \%$ of the people worldwide live in areas exceeding the WHO guideline for healthy air, and more than half live in areas that do not even meet WHO's least stringent air quality targets. According to WHO estimates, ambient air pollution and indoor air pollution caused globally 4.2 and 2.8 million deaths, respectively in 2016 [2]. The WHO report further states that more than $40 \%$ of the world's population still does not have access to clean cooking fuels and technologies in their homes. WHO also recognizes that air pollution is a critical risk factor for non-communicable diseases. Nearly a quarter of deaths from heart diseases and stroke are due to air pollution; $43 \%$ of chronic obstructive pulmonary disease (COPD) deaths and $29 \%$ of lung cancer deaths are also due to air pollution [2]. The above facts confirm that air pollution is affecting our health in a big, detrimental way and respite from this menace is not in site yet for most of the citizens of developing world. The direct effect of air pollution on respiratory health and precipitation of acute cardiovascular events in vulnerable group are well documented, but evidence is emerging that incriminates the role of air pollution in undesirable outcome of pregnancies for the mother as well as the child. Air pollution is emerging as a risk factor among women for reduced pregnancy occurrence and miscarriage [3], and also the newborn for low birth weight, preterm birth and congenital anomalies [4,5]. Neurological disorders like attention deficit hyperactivity disorder (ADHD) and degenerative disorders also enlist air pollution as risk factors [6]. So far, most of the research related to health effects of air pollution has been conducted in developed countries, because data are available on exposure as well as outcome. In low- and middle-income countries, monitoring of air pollution is yet to be of adequate standard and sufficient coverage, and thereby limits use of such data in assessing true burden of its effect on health parameters of population of these countries. Similarly, there is lack of easy access to data on morbidities and mortality that can be used for developing predictive models specific to these countries, including India. It is true for argument's sake that pathogenesis may remain same but the true burden of effect and its distribution across the country, for the purpose of identification of hotspots of air pollution-related morbidity and mortality, can be mapped only when we have local data. The efforts being made in this direction are far from desirable. Several research teams are conducting piecemeal research due to lack of funds, and absence of research mandate and policy guidelines for the institutions that have the capacity to carry out such research. This often leads to duplication of work, incomplete coverage and inadequate methodologies. In this issue of Indian Pediatrics, a retrospective study comparing 200 low birth weight babies with 200 matched controls found no significant effect of exposure to second-hand smoke and pollution due to cooking fuel on birth weight of the newborn [7]. Before we accept the conclusions of such studies, we need to go deeper and make real time, measured exposure to these parameters in terms of duration, quantity and speciation of exposure and longitudinally observe its effect on growth during the pregnancy period, after adequately controlling for confounders and adjusting for other known risk factors. It is important to keep in mind an innocuous caveat that air pollution is so universal that we may make the mistake of associating all illnesses with it, if we are not careful enough to consider biological plausibility of any such association.

On the other hand, we cannot wait for research-based evidence to start controlling the pollution, and that is why implementation and enforcement of strict laws to control the pollution at source and prevent exposure of population to pollutants is equally desirable. It is good to see that a study conducted in Shimla, published in this edition of Indian Pediatrics, assesses the extent of implementation of Cigarettes and Other Tobacco Products Act (COTPA) [8]. There are other studies examining the extent of implementation of COTPA in other parts of the country like Delhi and Karnataka $[9,10]$. But 
the true utility of this exercise will unfold only when it translates into action - when it compels the concerned authorities to rectify the lacunae in implementation of COTPA in the identified area, and sooner than later, the journal publishes the follow-up action so as to motivate others to take up the responsibility of conducting and reporting such studies related to improving the implementation of COTPA and other regulations and laws to save the future pregnancies and the next generation of newborns from the ill-effects of air pollution besides reducing the pollution at source itself.

Funding: None. Competing interest: None stated.

\section{REFERENCES}

1. Health Effects Institute. State of Global Air 2019. Special Report. Boston, MA: Health Effects Institute. Available from: https://www.stateofglobalair.org/sites/default/files/ soga_2019_report.pdf. Accessed September 19, 2019.

2. World Health Organization. Air Pollution. Geneva: WHO. Available from: https://www.who.int/airpollution/en/. Accessed September 19, 2019.

3. Guimarães MT, Cunha MG, Carvalho DP, Ribeiro TS, Martins LC, Braga AL, et al. Influence of environmental contamination on pregnancy outcomes. Environ Sci Pollut
Res Int. 2015;22:14950-9.

4. Gehring U, Tamburic L, Sbihi H, Davies HW, Brauer M. Impact of noise and air pollution on pregnancy outcomes. Epidemiology. 2014;25:351-8.

5. Bobak M. Outdoor air pollution, low birth weight, and prematurity. Environ Health Perspect. 2000;108:173-6.

6. Aghaei M, Janjani H, Yousefian F, Jamal A, Yunesian M. Association between ambient gaseous and particulate air pollutants and attention deficit hyper activity disorder (ADHD) in children: A systematic review. Environ Res. 2019;173:135-56.

7. Jayaraj NP, Rathi A, Taneja DK. Exposure to household air pollution during pregnancy and birthweight. Indian Pediatr. 2019;56:875-6.

8. Chaudhary A, Thakur A, Chauhan T, Mahajan A, Barwal VK, Chamotra S, et al. Creation of a smoke-free environment for children: An assessment of compliance to COTPA 2003 legislation in an urban area. Indian Pediatr. 2019;56:837-40.

9. Rijhwani K, Mohanty VR, Balappanavar AY, Hashmi S. Compliance assessment of Cigarette and Other Tobacco Products Act in public places in Delhi government hospitals. Asian Pac J Cancer Prev. 2018;19:2097-102.

10. Hebbar PB, Bhojani U, Kennedy J, Rao V. From policy to practice: Lessons from Karnataka about implementation of tobacco control laws. Indian J Community Med. 2017;42:77-80. 